Volume 3

Number 3 Virtual Platforms: Spaces of Control

and Contestation

2018

\title{
Virtual Avatars: Trans Experiences of Ideal Selves Through Gaming
}

Kai Baldwin

The New School

Follow this and additional works at: https://digitalcommons.uri.edu/mgdr

Part of the Anthropology Commons, Digital Humanities Commons, Lesbian, Gay, Bisexual, and Transgender Studies Commons, and the Sociology Commons

\section{Recommended Citation}

Baldwin, Kai (2018) "Virtual Avatars: Trans Experiences of Ideal Selves Through Gaming," Markets, Globalization \& Development Review: Vol. 3: No. 3, Article 4.

DOI: 10.23860/MGDR-2018-03-03-04

Available at: https://digitalcommons.uri.edu/mgdr/vol3/iss3/4

This Article is brought to you for free and open access by DigitalCommons@URI. It has been accepted for inclusion in Markets, Globalization \& Development Review by an authorized editor of DigitalCommons@URI. For more information, please contact digitalcommons-group@uri.edu. 


\section{Markets, Globalization \& Development Review}
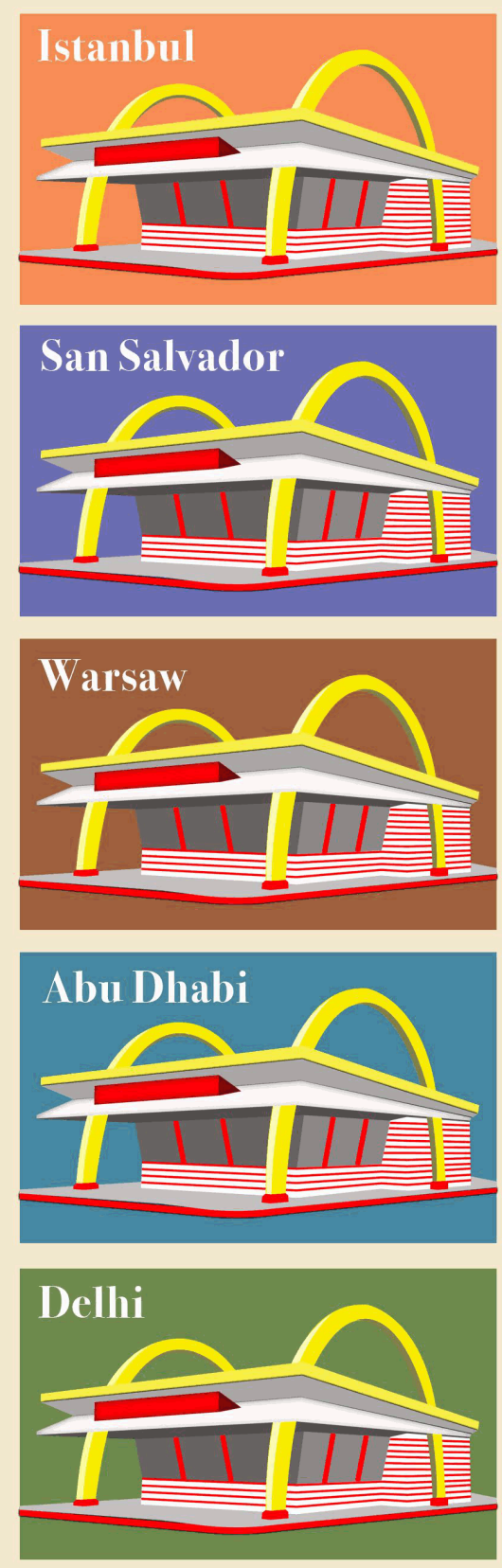
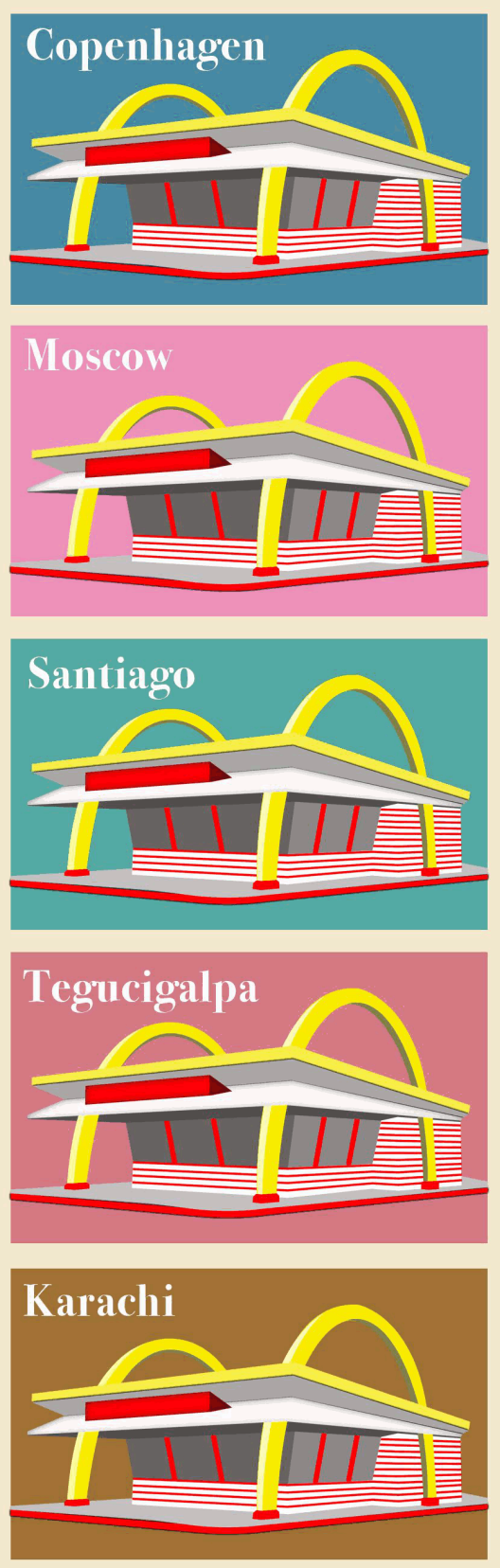
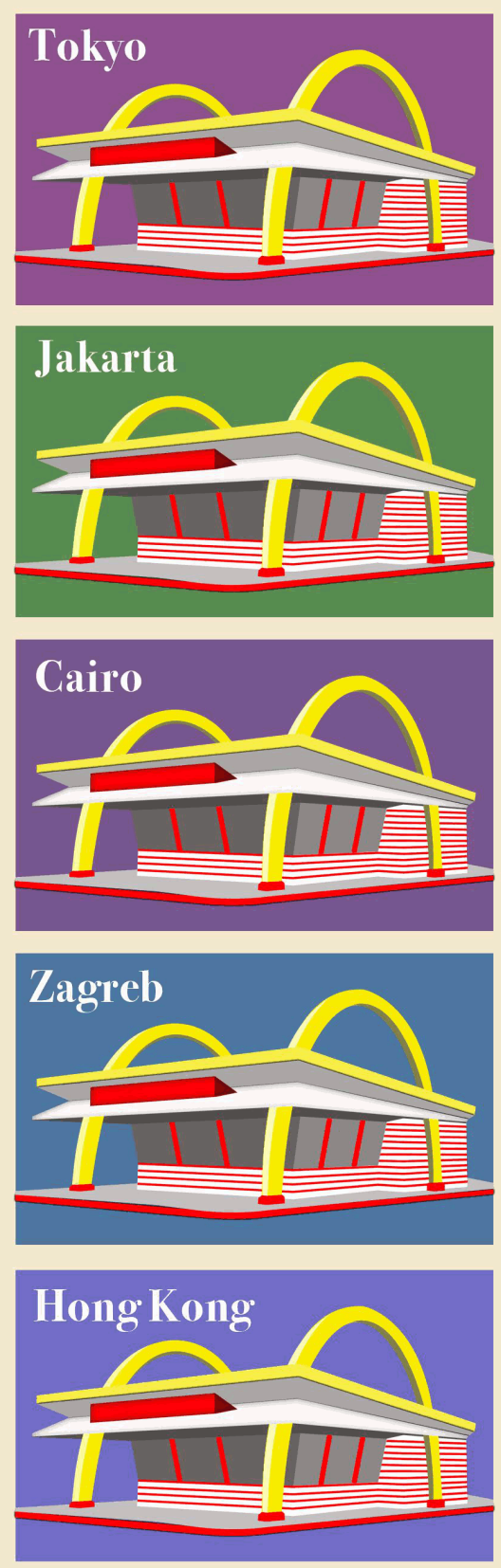

This article is available in Markets, Globalization \& Development Review: https://digitalcommons.uri.edu/mgdr/vol3/ 


\section{Virtual Avatars: Trans Experiences of Ideal Selves through Gaming}

\section{Introduction}

Video games have become a major part of our culture since they were first introduced in the 1970s. We need only look at the recent explosion of games like Fortnite or Minecraft for proof of this. Fortnite in particular has so permeated American culture that it has received attention on national news, described as an epidemic, and even parodied on Saturday Night Live. The most immersive of these games are MMORPGs (massively multiplayer online role playing games) where players interact with hundreds of other players in the game worlds. Escaping to a virtual world can be a way to relieve stress, escape unpleasant realities, or simply have fun. However, for some people, gaming becomes much more than that. One of the main characteristics of most games is the creation of an avatar - a digital representation of the gamer's body in the virtual world. Avatars are often extremely customizable, including things such as the shape of the nose or the size of the feet in addition to the more obvious things like gender and height.

This customization allows players to construct a virtual body completely independent from the limitations imposed by physical existence. Consequently, the virtual world itself becomes a site for identity construction, where users are free to experiment with and perform idealized or alternative selves. Transgender people experience conflict between their minds and bodies - the physical characteristics of their bodies do not correspond to their gender identity. The discomfort caused by the mismatch is referred to as dysphoria. Avatar creation can relieve dysphoria and empower transgender individuals to experiment with the embodiment of their ideal physical selves. Through this process, trans gamers are creating emergent narratives - player actions unanticipated by the designers. As Brown (2018) states, "The emergent game allows for the radical reappraisal and reconfiguration of the self through the degree and 'type' of emergence allowable by the system."

Although many researchers have studied embodiment in virtual environments, there has been very little investigation of how that embodiment affects transgender experiences online. One of the major questions about virtual embodiment is whether users are expressing an idealized self through their avatars and presentation. Thus, this project is important in two ways: first, to bring awareness to the experiences of a minority group, and second, to help further the investigation of ideal selves. 


\section{Literature Review}

Both qualitative and quantitative methods have been used to research the expression of ideal selves through avatars. Sherry Turkle was one of the first scholars to examine the possibilities of identity construction in virtual worlds. She investigated text-based RPG experiences (MUDs - multi-user dungeons) in the 90 s, and described these early types of virtual worlds as laboratories for experimenting with identity building (Turkle 1997, p. 180). The anonymity embraced by most virtual worlds allows users to explore aspects of their identity they might hesitate to express in the physical world. Turkle views these environments as "objects-to-think-with" (Turkle 1997, p. 213) - tools players use to help them think about identity. "When people adopt an online persona they cross a boundary into highly-charged territory. Some feel an uncomfortable sense of fragmentation, some a sense of relief. Some sense the possibilities for self-discovery, even self-transformation" (Turkle 1997, p. 260).

The MUD users Turkle spoke with often referred to their online personas as ideal selves: "A twenty-six-year-old clerical worker says, "I'm not one thing, I'm many things. Each part gets to be more fully expressed in MUDs than in the real world. So even though I play more than one self on MUDs, I feel more like 'myself' when I'm MUDding"' (Turkle 1997, p. 185).

Andrew Thomas and Mark Johansen asked female participants to create two different avatars in Second Life. For the first avatar, the women were asked to create an avatar who resembled their physical bodies as closely as possible. For the second avatar, however, no design restrictions were given, and participants were free to create any type of avatar they wished. Thomas and Johansen used the first avatar as a baseline, so they could easily see which physical attributes were being changed when the women were allowed to create an avatar without restrictions.

After comparing the avatars and surveying the participants, they found that women who expressed a desire to have a lower body weight created avatars who were thinner than their physical bodies (Thomas and Johanssen 2012, p. 48). Although this trend is not surprising, it provides clear evidence that people use avatars to choose an embodiment they view as ideal. "When presented with a blank canvas with which to represent themselves, people have a tendency to let the ideal characteristics they hold inside, out" (Thomas and Johanssen 2012, p. 52).

A similar study conducted with male participants had comparable results. In this case, the men were asked to describe their ideal bodies before they created avatars. Researchers discovered that the larger the disparity between gamers' actual and ideal body types, the more they 
tended to overcompensate when creating avatars. Instead of simply creating an ideal avatar, the men tended to create avatars that were actually more muscular than either their actual or ideal body descriptions (Cacioli and Mussap 2014, p. 146). This shows that body image issues are not restricted to one gender or another, and that avatars can be used to compensate for a disparity between the physical body and the ideal body.

In a study conducted on users of three popular MMORPGs, researchers found that many users enacted an ideal self through their avatar. However, they also made an interesting find regarding the difference between physical idealism and personality idealism. "[W]hile users apparently grow more attached to their avatar if its body differs significantly (in an idealized way) from theirs, it looks as if great differences in personality between the two actually reduce satisfaction. In other words, trying to behave in a very different way from one's offline self in VWs [virtual worlds] is not particularly satisfying" (Cacioli and Mussap 2014, p. 157). Thus, players become attached to their avatar and identify with it strongly when it is an ideal representation of themselves physically. However, trying to live in the virtual world with an ideal personality rather than their own personality actually leads to them being less attached to that avatar. The authors conclude that players are more interested in transforming their bodies than their personalities in virtual worlds. This conclusion supports the idea that users are constructing an authentic ideal self, since they cannot become attached to an avatar who acts vastly different from themselves.

\section{The Intersection of Media Theory and Queer Theory}

Gilles Deleuze and Felix Guattari propose a theory of identity where the self is composed of a series of desiring-machines. Thus, rather than being one simple entity, the self is a multiplicity of desires. The desiring-machines are constantly involved in producing and reproducing various aspects of identity. This composes an organism which Deleuze and Guattari refer to as the "body without organs" (BwO). They refer to the BwO as an egg of pure potential:

The body without organs is an egg: it is crisscrossed with axes and thresholds, with latitudes and longitudes and geodesic lines, traversed by gradients marking the transitions and the becomings, the destinations of the subject developing along these particular vectors. Nothing here is representative; rather, it is all life and lived experience: the actual, lived emotion of having breasts does not resemble breasts, it does not represent them, any more than a predestined zone in the egg resembles the organ that it is going to 
be stimulated to produce within itself. Nothing but bands of intensity, potentials, thresholds, and gradients (Deleuze and Guattari 1983, p. 19).

Like an egg, the BwO contains the potential to develop into absolutely any identity or state of being. There are no limits on the identities or personalities the BwO can emanate.

This is a difficult concept to understand, but one well worth considering carefully. If we picture the $\mathrm{BwO}$ as the center of a system, it itself is stable, nonproductive, and imageless. The desiring-machines which create the self surround the $\mathrm{BwO}$ and are constantly producing identities, images, personalities, etc. What Deleuze and Guattari refer to as the "subject" is what we would normally think of as the self. This subject, rather than being the center of the system, is located on the periphery. It is fluid and multiple, constantly being changed and recreated by the desiringmachines emanating from the $\mathrm{BwO}$. The self is thus in a constant state of becoming. Identity never arrives at a final destination, but continues to pass through a series of these states indefinitely. The $\mathrm{BwO}$ can never be completely attained, but functions as a limit towards which human nature strives. The goal is to move away from the constantly shifting states of identity towards a state of pure potentiality.

This is a useful concept for this project, because I argue that we can view identity construction through avatars as a step towards this BwO. This challenges the assumption that online identities are necessarily false by asserting that all identities are fluid and multiple. The fact that online identities and avatar representations are more obviously fluid is actually a sign that they are closer to the reality of human identity than an offline identity defined by stability. Avatars can change appearance, gender, and personality at will, reflecting different aspects of desire through a fluid identity. They are a constant process of becoming, a liminal space where identity can be explored and constructed without restraint or consequences. This is demonstrated most clearly by transgender experiences with avatars. For trans gamers, avatars function as an external $\mathrm{BwO}$, allowing them to exist temporarily as an ideal self, and often relieving dysphoria.

I am not the first to make the connection between the BwO and avatars. Christine Liao described her subjects' avatars as BwOs when she studied the habits of Second Life fashion bloggers. These gamers used the virtual world of Second Life to model fashion trends. Their blogs included images of the avatars and descriptions of their digital clothing. Liao noted that in this setting, the virtual bodies become a location for the production of desire. 
By choosing an avatar, we make some aspects of our desires visible. In this way, the avatar functions as a place where transformations can take place, and the virtual body remains closely connected to the physical body, which is the basis for the virtual body's identity...That is, avatar creation has its own affect/function, such that it cannot be reduced to a technique or skill that serves the construction of identities. And, the avatar, whether as another assemblage or a $\mathrm{BwO}$, cannot be seen as an object of desire or as a subject with a fixed identity; rather, it is becoming (Liao 2011, pp. 103-104).

Liao backs up her claims by pointing out how the bloggers' desires are projected through their avatars. One blogger envied her avatar because it possessed a tattoo she wished she had on her physical body, and another explicitly used her avatar to explore which types of fashion she would like to purchase for her physical body. Liao concludes by noting that "the projection of the self through an avatar body is unavoidable" (Liao 2011, p. 125).

I am also not the first to make a connection between Deleuze and Guattari and queer identities. A book entitled Deleuze and Queer Theory was published in 2009 which collects a number of authors discussing how the $\mathrm{BwO}$ and other concepts can be connected to queer theory. Many of the authors immediately point out that just as the $\mathrm{BwO}$ is a process of becoming, so trans identities are a process of becoming. A trans person can never become a cis person (a person whose assigned sex and gender are the same), and thus are always striving towards a limit that will never be reached (Conley 2009, p. 28).

Margrit Shildrick specifically discusses Deleuze and Guattari in the context of trans identities. Her primary field of research is in disability studies, so she uses the anomalous bodies of trans people as a jumping off point to get to a Deleuzian approach to disability. Shildrick describes the $\mathrm{BwO}$ as "the body in a process of corporeal becoming, that mobilises desire as a fluid indeterminacy that has no fixed aim or object, and which could always be otherwise" (Shildrick, in Nigianni and Storr 2009, p. 121). She argues that the $\mathrm{BwO}$ was never intended to be incorporeal, but simply to reject any (even temporary) stable identity that would give the subject an end to becoming. Seen through this lens, bodies which do not fit into society's ideas of "normal" do not need to be feared. "These are bodies that come together - and break apart - in multifarious ways, always frustrating the anticipated outcome of performativity in consistent sexual identities...[A]nomalous bodies are no longer a source of anxiety, but hold out the promise of productive new becomings" (Shildrick, in Nigianni and 
Storr 2009, p. 125). Trans bodies are thus transformed from transgressive or taboo to a positive sign of becoming.

Judith Butler, one of the most prominent queer theorists, also describes queer identities in terms of becoming. She refers to gender as a state of doing rather than a state of being, and uses language that could easily be applied to a BwO in her descriptions. "Consider the further consequence that if gender is something that one becomes-but can never be - then gender is itself a kind of becoming or activity, and that gender ought not to be conceived as a noun or a substantial thing or a static cultural marker, but rather as an incessant and repeated action of some sort" (Butler 1999, p. 143). The characteristics that society stereotypically assigns to one gender or another are then a performance rather than being inherently present. Those characteristics function to construct a gender identity instead of being "symptoms" of a particular gender identity. "As the effects of a subtle and politically enforced performativity, gender is an "act," as it were, that is open to splittings, self-parody, self-criticism, and those hyperbolic exhibitions of "the natural" that, in their very exaggeration, reveal its fundamentally phantasmatic status" (Butler 1999, p. 187). Trans people, then, are using gender performance to construct an identity which does not correspond with the gender identity corresponding to the sex they were assigned at birth. But this identity never reaches an end - it remains in a constant state of doing or becoming. Thus, the trans experience itself functions as a BwO. A video game avatar is simply an extension of the already existing BwO into the virtual world, the projection of an external BwO.

\section{Methodology and Fieldwork}

Having observed several trans gamers using avatars to experience an ideal embodiment, I conducted a series of interviews to investigate their experiences and find out whether the phenomenon was common. In order to find participants, I made posts in several Facebook groups, most of which are dedicated to FTM individuals (female-to-male transgender people). Access to these groups is limited to those who are transgender themselves. Thus, since I am a trans person myself, I had access to a space where I could easily find subjects to interview. It proved to be more difficult to find MTF (male-to-female) participants, but by asking the men I interviewed if they knew any trans women who might be willing to participate, I was able to talk to several women as well. All respondents gave informed consent for their words (and images of their avatars) to be used for this project.

For this research project, I interviewed approximately 30 individuals ranging in age from 18 to middle-aged subjects who declined to share their 
ages. The in-depth interviews consisted of open-ended conversations in which we discussed avatars and each gamer's relationship to their avatar. I avoided leading questions that would encourage a certain response, and questions with simple yes or no answers. I found that sharing my own experiences with avatars was useful for eliciting more detailed descriptions. Explaining how l'd noticed myself using avatars to visualize myself as I wished to look, and how that led to this project, gave me something in common with my participants. In addition, it set me apart from most researchers trans people have encountered, who simply want to know why they are trans. Many trans people are understandably reluctant to talk to researchers after encountering multiple people who just want to question their identity or existence.

Robert Kozinets was one of the first researchers to bring participant observation into the setting of online forums and message boards. These were precursors to social media sites like Facebook, Twitter, and Reddit. $\mathrm{He}$ referred to his methodology as netnography, and denied any division between the digital world and the physical world. Because of this, he argued that instead of viewing digital content only through the lens of content analysis, researchers should use any of the methods they would use if their subjects were available in a physical location. In addition, the data collected digitally should not be seen as inferior to traditional ethnography, but rather should be seen as simply a different type of ethnography.

In his 2010 book, Kozinets briefly mentioned the possibility of using netnography to investigate digital worlds, pointing out how important participating is in such a setting. "Because virtual worlds involve a 'reembodiment,' a new sense of world or 're-worlding,' and an ability to inhabit multiple worlds in multiple bodies or multiperspectivality, many of the most interesting aspects of the phenomena are experienced from a subjective point of view that is not easily captured through interactions or interviews with others" (181). I agree with this perspective - it is difficult to understand how immersive a virtual world can be unless you have experienced it firsthand. I have spent hundreds of hours participating in virtual worlds prior to this investigation, and my own experiences there have greatly assisted this project. I have been able to understand common gaming jargon and cultural norms without the need for extensive research, and thus interviews proceeded much more smoothly than they would have otherwise.

All interviews were conducted via Facebook Messenger. Although it is not the usual setting for such interviews, instant messaging in this case has certain advantages. First, most of the gamers I interviewed were below the age of 25. People of this age have grown up in a world where digital communication is the norm - they are "digital natives," if you will. Thus, they 
are comfortable using this medium to have in-depth discussions. Indeed, many are more willing to discuss details of their experiences in this manner than they would be in a face-to-face or phone interview. For trans gamers in particular, this effect is increased. Many of the people I talked with mentioned their extreme dislike of phones or voice chat due to voice dysphoria (mental distress caused by a voice that causes people to assume their gender is not the one they identify with). Most trans people desire to avoid any indications of the gender they were assigned at birth and which has been culturally imposed on them, and thus are more comfortable in a setting where neither their voice nor their physical characteristics can be observed.

As a final note, all names have been changed to protect the privacy of participants. In addition, all quotations appear exactly as they were sent to me. Any spelling errors or punctuation quirks were present in the text of the messenger chat. In some cases, such errors can give just as much information as facial expressions in face to face interviews. Often when the gamers I was interviewing became particularly excited about a topic, they would type faster and make more mistakes. I thus believe it is important to preserve these (and any emojis used), because in text-based communication, they function similarly to body language.

\section{Interview Results}

Out of the trans gamers I interviewed, more than two thirds explicitly stated they have used video game avatars to experiment with their ideal physical presentation, thus engaging in the creation of emergent narratives. Those who claimed not to had differing reasons as to why they did not. Craig stated that while he was in the early period of his medical transition process, he felt that it was "more powerful or more appropriate" to create male avatars. However, this need ceased once he began to pass (once he was assumed to be male by strangers) in public settings. He then reverted to playing games as female characters, largely because "they're more appealing to watch running around the screen." Interestingly, many cisgender men (those who identify with the gender they were assigned at birth) gave the same reason for playing female characters in Bonnie Nardi's study of World of Warcraft players. One of her interviews led to this comment: "If I have to look at someone's ass for three hours, it's going to be a girl's" (Nardi 2010, p. 159).

Colton, on the other hand, an avid gamer and grad student, stated that he has never felt the need to have an avatar function as an ideal body. In fact, as he described his favorite avatar, he said, "the purpose of Zri was to see if I could accomplish a gender neutral character with such strict 
gender regulations. I wanted to see if I could fuck the binary." The game in question is Elder Scrolls Online, which requires users to choose between male and female, and restricts armor choices based on that gender choice. Colton wanted to create an avatar whose gender would be ambiguous and impossible to pin down. He chose to use a black khajiit (sentient cats who walk on their hind legs in the Elder Scrolls universe) with a base "female" gender and go from there. Having seen screenshots and visited Zri's home in ESO myself, I have the impression that his attempt at deconstructing the idea of the gender binary was quite successful.

Figure 1: Colton's avatar Zri (black khajiit with silver armor on the far left)

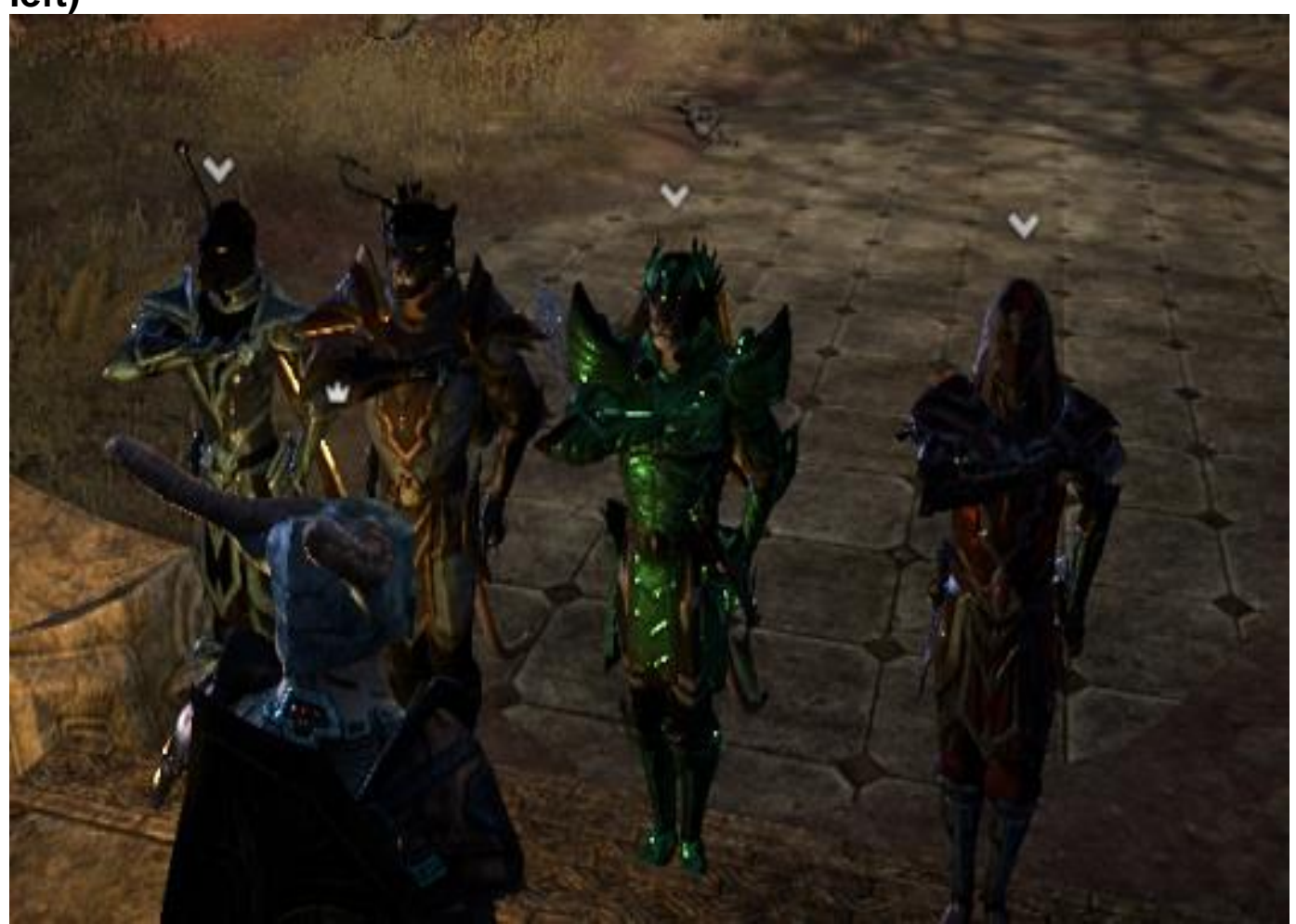

Source: screenshot obtained from Colton

Colton acknowledged the concept of creating an ideal self, but explicitly rejected it. He gave me a detailed explanation of this rejection:

I think I like challenging people's biases more than I care for people seeing and accepting me as the person I am. I'd much rather have my "fuck the binary" avatar and having people question and ponder Zri than "fuck yeah, I'm a guy. See. Look at me. I'm a guy. A hot, shirtless guy." I mean. I get the appeal of being the ideal version of 
yourself, but I don't need an ideal vision. I want people to see me and accept me as I am not who I will become through surgery, hormones, and/or changes to my body type. I'd rather learn to love myself as I am than seek a constant "I need to do this, then I can be happy with what I see in the mirror".

Colton is the only person I interviewed who was so self-reflective. He is also unique in that he is the only person I interviewed who is currently in grad school. Since he is working on a master's degree in gender studies, it makes sense that he would be more introspective about this topic than my other subjects.

The majority of participants, however, expressed an identification with their avatars to various degrees. They place an emphasis on being able to choose attributes stereotypically associated with their gender identity in virtual worlds. Several of the men mentioned that one of their favorite things to do in games is to run around the virtual environment shirtless - something a person with a body assigned female is restricted from doing in the United States and most other countries. A flat chest, facial hair, tattoos, and muscles were among the most desired characteristics among the trans men, while trans women talked about breasts, hair, and clothes more than any other characteristics. Most explicitly stated they were giving their avatars the characteristics they wished they could possess in their physical bodies. When asked why certain physical aspects of his avatar were so important to him, Landon stated, "They're traits I wish I had." His comment is indicative of the feelings of these respondents. Nathan described his avatar as "an inner me," while James referred to his as "an extension of myself."

When asked to describe their avatars, several gamers became intensely engaged and offered detailed descriptions. For example, Nathan said,

I wanna make him as real as I possibly can. In GTA you can even get down to the texture of their skin. I wouldn't ever pick a female character, that just seems bizarre to me. Not because females shouldn't play, of course not! But because I'm able to represent my true self through a character I pick male. I like my guy to have lots of tattoos, because I am tattooed and I plan on being covered. I pay quite a lot attention to my guys fashion sense, because I feel uncomfortable in the clothes I want to be able to wear. I feel like my character wears them for me.. it's actually really hard to explain. No one has ever asked me about my character so now I'm talking about 
him it's kinda tricky. But the one thing I can say is that I have an attachment to my guy because he's me.. if you get me?

The question I had asked him was which physical characteristics of his avatar were most important to him. Notice the repeated periods, spelling errors, and lack of punctuation. Throughout the rest of our conversation, Nathan's responses were much more mindful of grammar. His eagerness to express his feelings about the avatar caused him to type faster and make more mistakes than he did normally.

Clearly, Nathan identifies very strongly with his avatar. In fact, he even commented that his avatar helped his relationship with his fiancé.

My fiancé noticed my attatchment to him and said "he's your inner man isn't he?" And I said "yup!" She replied "he's sexy!" And this made me feel amazing.. because if she finds him sexy then she will still find me sexy as a boy because he's pretty much how l'll look.

Her validation of the physical attractiveness of the avatar was interpreted as a validation of him. Since he had carefully designed the avatar as his ideal body, he was connected to it to the extent that there ceased to be much of a distinction between himself and the avatar. Furthermore, Nathan sees his avatar as representing his true personality and behavior as well as appearance. He described several choices he made in the game based on his moral opinions, because his character could not do anything that he himself could not do.

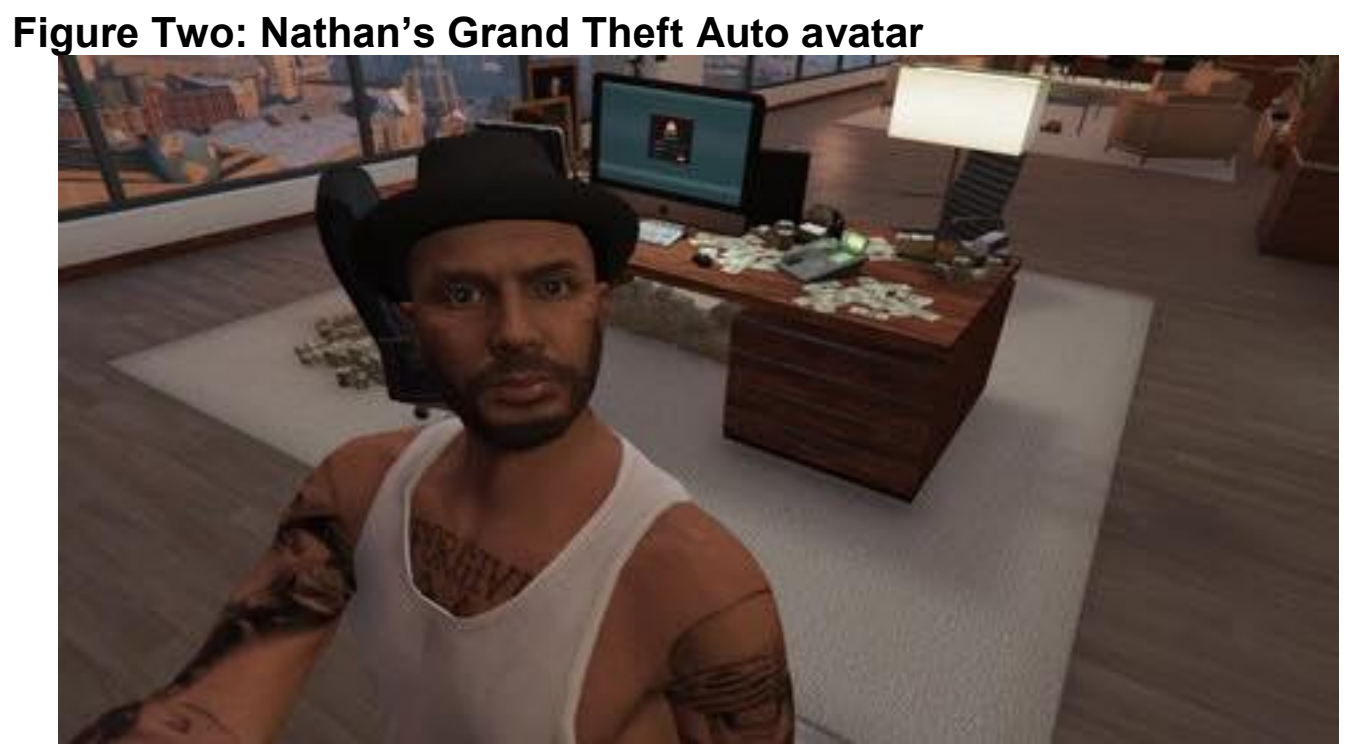

Source: screenshot obtained from Nathan 
James took this identification with his avatar even further. In addition to creating an avatar he would like to physically emulate in the future, he also role plays as his character. James plays World of Warcraft (WoW), an MMORPG (Massively multiplayer online role playing game) which has less customization options than many games. Players are able to choose gender, and then choose from about a dozen preset options for hair, facial expression, hair color, and facial hair. Although the entire game is technically a role playing adventure, some players take this a bit further, developing back stories, personalities, homes, and careers for their WoW characters. Role players often have complex relationships with other players, including family and a spouse or significant other. James describes his main character as follows:

My main is an extension of myself, with an intricate backstory and a very exciting future. I like to apply my own morals and beliefs into my character, having him fight for what he believes in. Learning about blood elves and their history has been an amazing evolution that parallels with my journey with coming out and realizing that I am a man. I made my main character when I was coming out, and through him I was able to stabilize myself. All of my worries, fears, questions, insecurities, and overall depression were quelled when I played my blood elf. Discovering him and his history, and writing his story, helped me discover my own story as well...Not to mention that I find blood elf men extremely attractive, with their long ears and long eyebrows and goatees and all [Note the use of emojis to convey something that would be difficult to express in words. James used this particular emoji nearly every time he mentioned his avatar's physical appearance.] I am also very attracted to the feminine male aesthetic.

Thus, it was not only the physical appearance of the avatar that helped James experience an ideal embodiment, but also his story and interactions with other players. He identifies with this character to the point that they share a name. The blood elf is also named James. It is interesting to note that the avatar had the name first (because of this, I have also changed the name of the avatar) - James changed his name to match the avatar he views as a part of himself.

As James stated above, he and his avatar share many aspects of their history. He gave me several key details about the avatar's in-game persona. When avatar James was young, he spent years saving up enough gold to afford gender transformation from a mage and an alchemist. Avatar James is also gay, and has an in-game boyfriend named Tydrien. In 
addition, James states, "He is definitely my \#bodygoals and \#relationshipgoals LOL! And a lot of what he believes in morally and politically align with me in real life." Last summer, James attended a local convention while cosplaying as his avatar. He also creates fan art of avatar James and Tydrien. Thus his identification with the avatar extends outside of the virtual environment. The boundary between James and his character has become so blurred that it nearly does not exist.

\section{Figure 3: Avatar James}

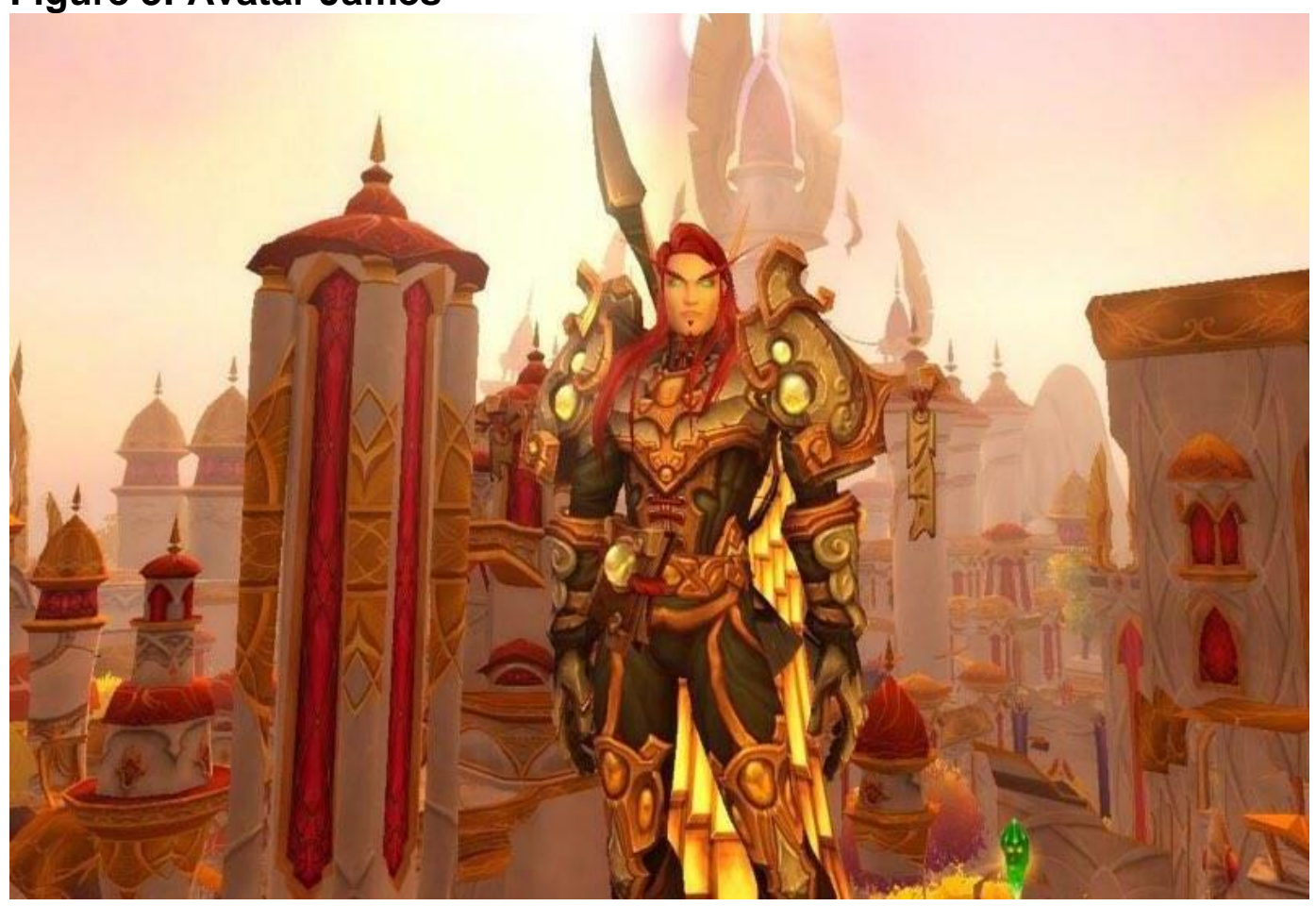

Source: screenshot obtained from James 
Figure 4: James' fanart of his avatar

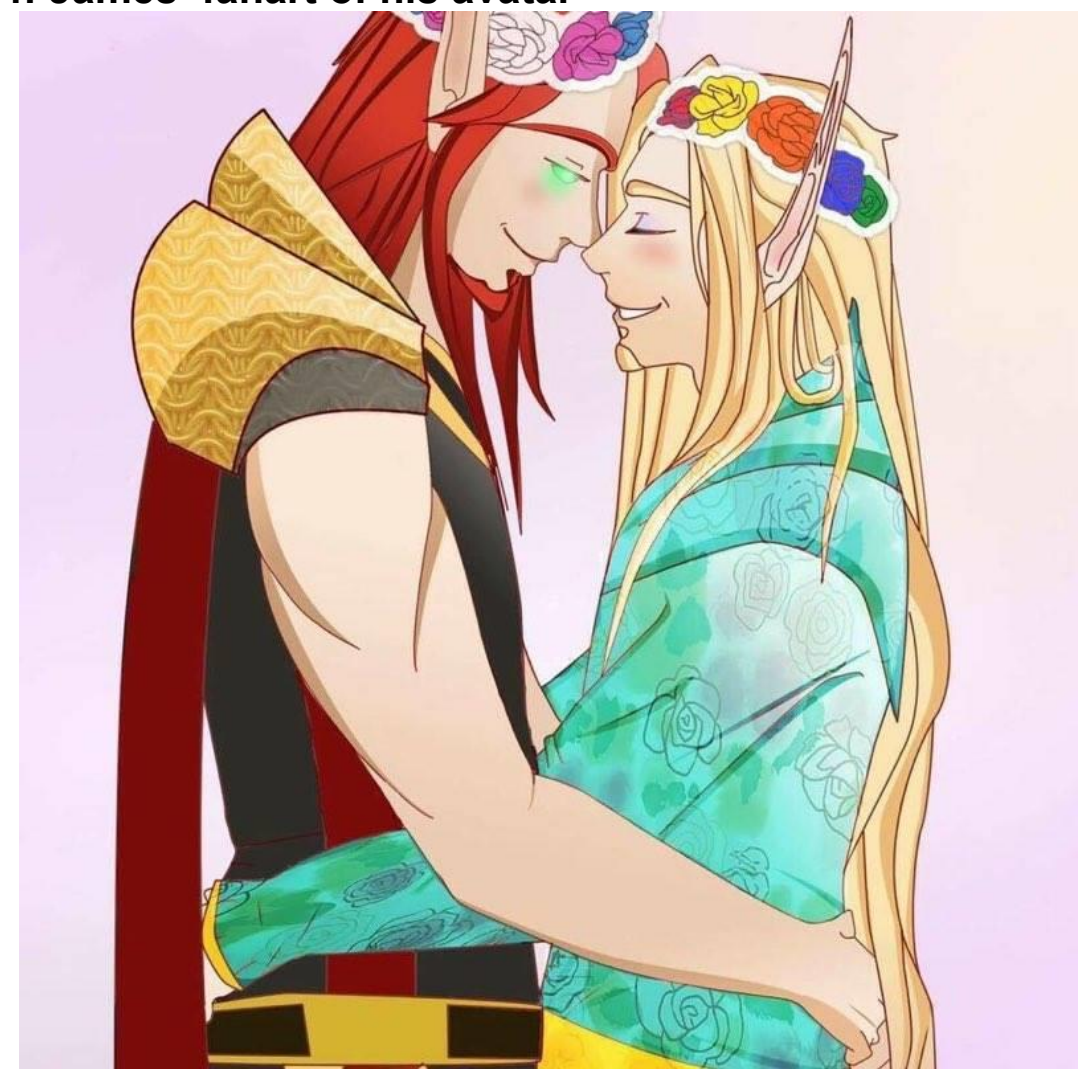

Source: screenshot obtained from James

One respondent in particular had a more complicated relationship with his avatar. Kyle acknowledged that he plays exclusively as a male character because he is uncomfortable "being" female, even in a virtual setting. He explicitly stated, "I always play Males. As an extension of myself." However, he also denied using avatars to visualize transition goals. Instead, he noted that since he is gay, he wants his avatars to be sexually attractive, echoing the man from Nardi's book who wanted to look at an attractive female while gaming. "I love myself and I dont want to be someone I am not. It would be impossible to make a character look like myself so I make more character look like dudes Im attracted to." Thus Kyle simultaneously uses a male avatar as an extension of himself and as a sexual fantasy.

In general, the women I talked to focused much less on physical characteristics than the men did. However, this does not necessarily indicate that trans women do not care about physical attributes. Despite recent progress, video games remain a generally sexist environment, and 
female avatars often have less customization choices than male ones. As Susan points out, "Most games idealize the female figure anyway." An article written to explore the phenomenon of a genderswapped character from Mass Effect expands on this observation. The character in question, Commander Shepherd, was designed as a cis man and intended to be played that way, but late in development the company who made the game included an option for gamers to make the character female. It was not well done, however - the female Shepherd had many less spoken lines than the male and the animations were not as clean for her movements. Playing as female Shepherd was seen as transgressive since the character was "meant" to be a man. "Female bodies are often oversexualized and scantily and dressed, and therefore made ready for the male gaze. The powerful and muscular male character, on the other hand, represents the concept of hegemonic masculinity, the normative pattern of practice which embodies the most honored way of being a man" (Krobova, Moravec and Svelch 2015, p. 40). Susan explained that she can easily tell when a straight cis man is playing with a female avatar, saying that they "tend to make twi'leks [an alien species from the Star Trek franchise] and overly sexualize them. They will be very aggressive getting involved in erotic role play and when there are dance parties." That situation is a great example of how female avatars are created with men in mind. Thus, since both available genders were created for the male gaze, female gamers are left with fewer options, since their avatars will always have exaggerated chests, hips, and movements in almost all games. With this in mind, it makes sense that every female gamer I talked to listed hair as their top avatar attribute - this is one of the few physical attributes with the same level of customization available as the male avatars.

Trans women gamers were most interested in simply being able to exist as women in the virtual world. Given that trans women are much more likely to be physically attacked than trans men are, this makes sense. Being a woman in a virtual world is physically safe - there is always the danger of transphobic comments and verbal abuse, but the physical body remains safe. Toni wrote, "I remember Professor Birch of Pokemon Sapphire fondly for being the first person to ask me 'Are you a boy or a girl?' and then accepting my answer without objections."'

\section{Dysphoria}

Extension of avatar relationships into the physical world was not something I had been expecting when I began the interview process. However, avatars appear to have either a negative or a positive effect on feelings of dysphoria. It was in my conversation with James that this was first brought to my 
attention. His detailed description of his avatar's backstory led me to ask about dysphoria, since it seemed that his life was intertwined with avatar James' story. He responded, "Whenever I'm experiencing dysphoria, I always imagine that I am James and in James' body instead of my own, and it often helps $\%$." In his case, then, the avatar provides a concrete object which can be visualized when feelings of dysphoria strike.

Nathan has a slightly different perspective. Rather than imagining himself as his avatar when dysphoria strikes, he finds that the experience of total immersion extends beyond the game. "I forget about my own reality, I completely forget I have a females body. I'm totally absorbed in him and the game. In my mind I'm him. Even after I come off the game I feel more masculine for a while." For Nathan, interacting with the virtual environment through a male body creates a positive feeling of identity affirmation that continues after he leaves the game and helps to alleviate negative body image.

Several other participants also agree that their avatars help them cope with dysphoria. Gage says that it "Boosts my self esteem a bit and its kind of reassuring. Its like i can play online and be anyone i want. I can the man ive always wanted to be amd theres no judgement." This seems to imply that the virtual environment functions as a space safe for experimentation. Caleb and Thomas both state that avatars help them deal with dysphoria, but only if they log into the game. Zane reports a combination of both feelings: "Some days I would feel great after logging off, but others I wouldn't want to quit playing because I couldn't handle the dysphoria any other way."

As can be expected, those who do not experience their avatars as ideal selves, also do not experience avatars as having any effect on their dysphoria. However, the majority of participants do experience positive effects.

The other side of this phenomenon is the discomfort caused when many trans men attempt to play as a female character. When I related a personal experience with this (I once spent months leveling a female character only to delete her when she made me too uncomfortable), James responded, "My ex pressured me into being a female character and I HATED it. I hated everything about it. lol!" This feeling is almost universally present. Thomas elaborates how female avatars make him feel: "female characters make me feel vulnerable and I bet you know how cruel some internet people are haha. It doesn't help that not only am I being made fun of but also playing a female character makes it even worse." It is not only the appearance of the avatar which causes the discomfort, but also the way other players interact with a user they assume to be female. 


\section{Analysis}

Several overall trends emerged from the collected interviews. First, the longer it has been since a person has made their trans identity public and began progress on any medical transition goals, the less likely they were to consciously experiment with gender in video games. Several mentioned being obsessed with every detail of their avatar's physical appearance before they came out or in the first few years after. However, the urge to customize every feature faded with time, and most became less interested in the details of the avatar as long as it matched their gender identity. This matches the way trans people often perform gender when they first begin transitioning. They tend to overemphasize masculinity and femininity through actions and dress, and fade into a more natural performance once they have had the chance to spend some time as their true selves.

Age also seems to be a factor affecting whether or not a person uses avatars to experiment with gender presentation. The younger the participant, the more likely they were to have used an avatar to visualize their transition goals. Older participants found it important to play as their true gender, but were less interested in the details of appearance. This, I think, can simply be attributed to generation gaps. The younger participants have grown up in a world where huge levels of customization are expected for almost every product, and video games are no different. When the older participants first began gaming, however, avatar customization was not yet possible - you simply chose a gender and played with a character who could not be changed beyond that choice. Therefore, they used the avatar to extend their gender identity into the virtual world, but not to visualize specific body changes.

Finally, nonbinary gamers (those whose identity lies outside of the stereotypical gender binary) tended to have a unique interaction with avatars. In general, they cared the least about trying to make an avatar look like they would like to look in the future. Instead, several described trying to make an avatar that obviously deconstructed gender roles, whether or not the character ended up sharing a resemblance to them. The most important thing in their case was simply to break down gender as a construct and try to escape the binary altogether by making an avatar whose gender was unable to be identified or who obviously transgressed the arbitrary gender boundaries. Nonbinary gamers expressed a desire to have an avatar system that would allow a user to start with a genderless avatar and add any physical characteristic whatsoever to that body. 


\section{Conclusion}

Based on the data presented here, trans gamers can clearly be seen using video game avatars to escape or transcend physical limitations and take a step toward the limit of a body without organs and an example of emergent gaming. Although I would argue that all people, regardless of their gender identity, have a fluid identity, trans people provide a particularly clear example. Given that most of the gamers I spoke with have multiple avatars across a variety of games (or even multiple avatars within a single game), the process of "becoming" an ideal self through an avatar is never finished. In the conversations I had, we generally focused on each person's main avatar, but all participants had other avatars as well. Each other avatar also contributes to a sense of self. Several participants mentioned having experimented with multiple avatars before settling on a favorite, but even those favorites change over time. Avatars, like the body without organs, possess the potential of expressing an infinite number of identities.

Studying trans experiences without questioning their existence both encourages those experiences and helps to begin the process of alleviating the social exclusion often imposed on those perceived to be different. As the video game industry attempts to become more inclusive of trans stories and characters, further investigation into this field would be useful. Games like the ones mentioned here are worlds designed primarily for profit, and the companies who produce them overwhelmingly adopt hegemonic values in order to maximize that profit. However, despite the hegemonic representation created by the platforms, trans and queer players are able to push back against and transform such representation through their identity performance. These emergent narratives have functioned both to transform the lives of players and to pressure the game producers to include queer stories and characters. The latest Dragon Age game includes a trans man as a main character, although unfortunately he is abused and ridiculed by several other characters in the game. The Summerfall expansion of Elder Scrolls Online includes a quest line where players discover that a mage's missing brother is now a woman and has adopted a new career as an artist. The most promising part of the quest is that there is no option in the many conversation choices to question her identity, ridicule her, or out her without her consent. As games and society slowly become more accepting and inclusive, it will be interesting to observe how trans experiences with games change. 


\section{References}

Bessiere, Katherine, A. Fleming Seay and Sara Kiesler (2007), "The Ideal Elf: Identity Exploration in World of Warcraft," Cyberpsychology and Behavior, 10 (4), 530-35. https://doi.org/10.1089/cpb.2007.9994

Brown, Logan (2018), "The Unfree Space of Play: Emergence and Control in the Videogame and the Platform", Markets, Globalization \& Development Review, 3 (3), Special Issue, Article 2.

Butler, Judith (1999), Gender Trouble: Feminism and the Subversion of Identity. New York, New York: Routledge.

Butler, Judith (2004), Undoing Gender. New York, New York: Routledge.

Cacioli, Jon-Paul and Alexander J. Mussap (2014) "Avatar Body Dimensions and Men's Body Image," Body Image, 11 (2), 146-55. https://doi.org/10.1016/j.bodyim.2013.11.005

Deleuze, Gilles and Felix Guattari (1983), Anti-Oedipus: Capitalism and Schizophrenia. Minneapolis, Minnesota: University of Minnesota Press.

Krobova, Tereza, Ondrej Moravec and Jaroslav Svelch (2015), "Dressing Commander Shepard in pink: Queer playing in a heteronormative game culture," Cyberpsychology: the Journal of Psychosocial Research on Cyberspace, 9 (3), 38-51. http://dx.doi.org/10.5817/CP2015-3-3

Kozinets, Robert (2010), Netnography: Doing Ethnographic Research Online. Los Angeles, California: Sage Publishing.

Liao, Christine (2011), "Virtual Fashion Play as Embodied Identity Re/Assembling: Second Life Fashion Bloggers and Their Avatar Bodies," In Reinventing Ourselves: Contemporary Concepts of Identity in Virtual Worlds, Anne Peachey and Mark Childs eds. London: Springer-Verlag.

Nardi, Bonnie (2010), My Life as a Night Elf Priest: An Anthropological Account of World of Warcraft. Ann Arbor, Michigan: University of Michigan Press.

Nigianni, Chrysanthi, and Merl Storr, eds. (2009), Deleuze and Queer Theory. Edinburgh, Great Britain: Edinburgh University Press.

Peachey, Anne, and Mark Childs eds. (2011), Reinventing Ourselves: Contemporary Concepts of Identity in Virtual Worlds. London: Springer-Verlag. 
Taylor, T. L. (2002), "Living Digitally: Embodiment in Virtual Worlds." From R. Schroeder (Ed.) The Social Life of Avatars: Presence and Interaction in Shared Virtual Environments. London: SpringerVerlag.

Thomas, Andrew G. and Mark K. Johansen (2012), "Inside Out: Avatars as an Indirect Measure of Ideal Body Self-Presentation in Females," Cyberpsychology: Journal of Psychosocial Research on Cyberspace, 6 (3), 48-53. http://dx.doi.org/10.5817/CP2012-3-3

Turkle, Sherry (1997), Life on the Screen: Identity in the Age of the Internet. New York, New York: Touchstone.

Wang, Jeff, Xin Zhao and Gary J. Bamossy (2008), "Avatar and Extended Self in Online Gaming," NA - Advances in Consumer Research, 35 940. 